\title{
Founding Editor-in-Chief Acknowledgments and Introduction to Special Issue
}

\author{
Robert Geffner ${ }^{1,2}$ \\ Accepted: 10 November 2020 / Published online: 14 November 2020 \\ (C) Springer Nature Switzerland AG 2020
}

In this final issue of 2020, it is also the end of my term as Editor-in-Chief of the Journal of Child \& Adolescent Trauma (JCAT) that I founded 14 years ago. We are ending my term with the current special issue and the special issue to lead off next year. I will move to Founding Editor-in-Chief Emeritus, or similar title, for the future. I am proud of what we have accomplished in the past 13 volumes with the special issues and emphasis on research and practice in dealing with child and adolescent trauma. In the past 15 years, the field of trauma has advanced in many ways and has become an accepted area of mental health/healthcare in general, and psychology more specifically. Our role was to expand this interest, enhance our knowledge base, and to focus on an age range of youth who experienced trauma but were too often under-recognized.

\section{Current Special Issue}

The current special issue continues with this goal. We have learned quite a bit about the effects of traumatic situations on youth, and that is the focus of this issue. The issue includes articles studying the symptoms of both basic and complex trauma resulting from psychological, physical, and sexual violence, and ways to respond to the children who have experienced one or more forms of trauma. Articles also include the co-occurrence of trauma with other types of disorders, such as substance abuse, eating disorders, as well as multiple types of abuse. Such situations, if of sufficient severity and duration, can lead to complex trauma and result in either internalizing or externalizing behaviors in children and adolescents. This topic is also covered in this issue.

Robert Geffner

bgeffner@alliant.edu

1 Institute on Violence, Abuse \& Trauma (IVAT), San Diego, CA, USA

2 Alliant International University, San Diego, CA, USA
Other articles discuss the effects on children in different settings, such as foster care, community residences, child protective services, hospitals, and in families, including across generations as well as intergenerational transmission of trauma. Examples of interventions are discussed from a research, as well as practice, standpoint. Two articles also emphasize the impact of trauma on spirituality, which has become more widely recognized in recent years, especially as a significant component of resilience. The importance of adverse childhood experiences is another area that the trauma field has recognized and emphasized in the past two decades, and these types of experiences are included in this special issue as well.

I am pleased that the guest editors for this special issue, Scarlett Yang, Nanette Burton and Morgan Shaw from the Institute on Violence, Abuse and Trauma, have been able to compile these articles for this special issue. They have done an excellent job of including a wide variety of perspectives in helping to move the field forward. This continues the goal of $J C A T$, and I am proud to be able to have this special issue to close out this year in which we have had more than our share of traumatic experiences from the COVID 19 pandemic, the effects of climate change, as well as with violence and abuse world-wide.

Acknowledgments It is a pleasure to recognize several key professionals who have served in various capacities for JCAT. It has been important since the inception of the journal to ensure a diverse, interdisciplinary group of professionals involved with all aspects of the editing process for JCAT. I am proud to say that we achieved this goal. I want to acknowledge the staff who will be ending their work with JCAT. Morgan Shaw has been the Publications Coordinator for several years, Nanette Burton has been the Senior Editorial Assistant for several years, and Scarlett Yang and Eric Mendoza have been the Editorial Assistants and responsible for much of the peer review process during the last two years. In addition, our Assistant Editors will also be leaving the journal. They have been responsible for finalizing the editing for several years once articles have been accepted. These include Brittany Crowell, Shannon McHugh, and Jessica Mueller. They have been instrumental in maintaining quality control for JCAT. 
I have been fortunate to have excellent Associate Editors over the past several years who will also be leaving this year. These include Barbara Knox, Amy Tishelman, Victor Vieth, and Jennifer Parker. I am very appreciative of Dr. Parker for her efforts in having the Child Advocacy Studies (CAST) program at the University of South Carolina Upstate work with us over the past 4 years to collaborate on the journal. The other Associate Editors have guest edited various special issues on important topics during the past decade. Their work has been very much appreciated.

Several Editorial Board members will also be resigning with this final issue. They include: Robecca Bokoch, Allison Brownlee, Ruth R. DeRosa, Daniel Flannery, George A. Gaither, Joe Grady Gaurav Kukarni, Joseph Spinnazola, Frances S. Waters, and Mosi Williams. I appreciate their work over the years in helping provide important feedback to authors, to our Editorial staff and to me in making decisions. These are volunteers, as are the Associate Editors, and none receive compensation for their time and efforts.

Lastly, I would like to acknowledge those reviewers who also have provided important feedback to authors on their manuscripts over the past several years. Those resigning include: Ernestine Briggs-King, Ann P. DePrince, Giles Feinberg, James Garbarino, Esther Jenkins, Richard Kagan, Rachel Lev-Wiesel, Michelle Lilly, Sarah Robinson, Viola Vaughan-Eden, Jeffery Wherry, and Denis Yukhenko.
Finally, I would like to acknowledge the following peer reviewers who have dedicated their time and have contributed to the quality of this journal throughout the production of Volume \#13 this year by providing important feedback to authors and to our staff: Margaret V. Austin, Ian George Barron, Elsie Beach, Ellen M. Chiocca, Christine Descartes, Jacquelynn Duron, Michelle Evans, Shefali Gandhi, Gary Gibson, Liena Gurevich, Tobias Hecker, Esther Jenkins, Maria C. JimenezSalazar, Gerry Leavey, Bethany Lee, Shanyan Lin, Lauren Marlotte, Abby Palmer Molina, Angela Powell, Sarah Robinson, Susan Sanders, Eileen Santa-Sosa, Cris Scaglione, Dawid Scigala, Jenelle R. Shanley Chatham, Lauren Stanley, Bruce Wampold, Ineke Way, Michael Weuste, and Zeev Winstok.

To all our readers, authors, guest editors, Editorial Board members, reviewers, and colleagues for 14 years, I want to let you know how much I have enjoyed my role with JCAT and in working with you in this field. I wish all of you best wishes in your future endeavors. Be safe and stay healthy! Thank you.

Sincerely,

Bob

Publisher's Note Springer Nature remains neutral with regard to jurisdictional claims in published maps and institutional affiliations. 